\title{
Clinical care and complicity with torture
}

\author{
In the light of US Central Intelligence Agency guidelines that limited routine care of detainees to \\ promote torture, Zackary Berger and colleagues call for sanctions against health professionals \\ who cooperate
}

\author{
Zackary Berger associate professor ${ }^{12}$, Leonard S Rubenstein senior scientist ${ }^{232}{ }^{3}$, Matthew DeCamp \\ assistant professor ${ }^{1212}$
}

\begin{abstract}
'Johns Hopkins School of Medicine, Division of General Internal Medicine, Baltimore, MA, USA; ${ }^{2}$ Johns Hopkins Berman Institute of Bioethics;
${ }^{3}$ Center for Public Health and Human Rights, Johns Hopkins Bloomberg School of Public Health; Correspondence to: Z Berger zberger1@jhmi.edu
\end{abstract}

The UN Convention against Torture defines torture as "any act by which severe pain or suffering, whether physical or mental, is intentionally inflicted on a person" by someone acting in an official capacity for purposes such as obtaining a confession or punishing or intimidating that person. ${ }^{1}$ It is unethical for healthcare professionals to participate in torture, including any use of medical knowledge or skill to facilitate torture or allow it to continue, or to be present during torture..$^{2-7}$ Yet medical participation in torture has taken place throughout the world and was a prominent feature of the US interrogation practice in military and Central Intelligence Agency (CIA) detention facilities in the years after the attacks of 11 September $2001 .^{8-11}$ Little attention has been paid, however, to how a regime of torture affects the ability of health professionals to meet their obligations regarding routine clinical care for detainees.

The 2016 release of previously classified portions of guidelines from the CIA regarding medical practice in its secret detention facilities sheds light on that question. These show that the CIA instructed healthcare professions to subordinate their fundamental ethical obligations regarding professional standards of care to further the objectives of the torturers. ${ }^{12}$

This document adds yet another disturbing element to our understanding of medical complicity in torture, suggesting a need to strengthen international and domestic ethical declarations to promote accountability for such complicity. ${ }^{13}$ As an executive order by the US President outlines continued transfer of prisoners to Guantanamo Bay,$^{14}$ and the President has not ruled out the use of torture, a response becomes all the more urgent.

\section{Medical guidelines on enhanced interrogation}

From 2002, the CIA operated secret overseas prisons where terrorism suspects were detained and interrogated using "enhanced" methods such as extended sleep deprivation, confinement in a small box, exposure to cold water and air, stress positions, and waterboarding. CIA's Office of Medical Services issued guidelines in 2003 and 2004 for medical officers (physicians, physicians' assistants, and nurse practitioners). Medical officers were told that they were responsible for ensuring that enhanced interrogation methods did not result in serious or prolonged physical injury or death, although the limitations still permitted practices widely recognised as torture. $^{1011}$ These guidelines were made publicly available in redacted form in 2009 .

The 2016 release includes previously classified information related to medical monitoring and examinations that facilitated torture, such as evaluating prisoners for evidence of cardiopulmonary disease, assessing the gag reflex, and keeping prisoners nil by mouth before waterboarding. In addition, the release made it clear for the first time that CIA directions covered routine clinical care, showing that official policy limited clinical care for the sake of torture.

\section{Limitations on clinical care}

The guidelines stated that medical officers had an "obligation to maintain the highest professional and ethical standards and deliver appropriate care," and that they "should never perform or threaten to perform a medical procedure or intervention that is not medically indicated." Examples below, however, show how the guidelines directed clinicians to abrogate this ethical commitment.

\section{Initial history and physical examination}

Limitations imposed by the CIA on healthcare professionals' clinical decision making began early in the detention of terrorism suspects. For instance, the initial history and physical examination was expected to take no longer than 15 minutes and to focus only on recent trauma. At the same time, medical officers were required to conduct non-clinical functions, including body cavity searches of the oral cavity, head, and area behind the scrotum and rectum.

\section{Ongoing medical care and treatment}

Once a suspect was detained, and after a comprehensive physical examination to "address in-depth any chronic or previous medical problems," the guidelines set out requirements for and limitations on ongoing medical care. They allowed for periodic medical checks and treatment for chronic conditions, but they 